\title{
NEUROBIOLOGY OF APATHY IN ALZHEIMER'S DISEASE
}

\author{
Henrique Cerqueira Guimarães' ${ }^{7}$ Richard Levy², Antônio Lúcio Teixeira', \\ Rogério Gomes Beato', Paulo Caramelli
}

\begin{abstract}
Apathy is considered the most frequent neuropsychiatric disturbance in dementia and its outcome is generally deleterious. Apathy can be related to a dysfunction of the anatomical-system that supports the generation of voluntary actions, namely the prefrontal cortex and/or the prefrontal-subcortical circuits. In Alzheimer's disease, pathological and neuroimaging data indicate that apathy is likely due to a dysfunction of the medial prefrontal cortex. Accordingly, in this review article, we propose a pathophysiological model to explain apathetic behavior in Alzheimer's disease, combining data from neuroimaging, neuropathology and experimental research on the role of orbito-frontal cortex, anterior cingulate cortex, basal ganglia and dopamine in decision-making neurobiology.
\end{abstract}

KEY WORDS: apathy, Alzheimer's disease, decision-making, orbito-frontal cortex, anterior cingulate cortex, basal ganglia, dopamine.

\section{Neurobiologia da apatia na doença de Alzheimer}

Resumo - Apatia é considerada a alteração neuropsiquiátrica mais freqüente nas demências e suas consequêencias são habitualmente deletérias. Apatia pode ser relacionada à disfunção do sistema anatômico responsável pela geração de ações voluntárias, conhecido com córtex pré-frontal e/ou circuitos pré-frontais-subcorticais. $\mathrm{Na}$ doença de Alzheimer, evidências neuropatológicas e de neuroimagem funcional indicam que a apatia é provavelmente decorrente da disfunção do córtex pré-frontal medial. Assim, neste artigo de revisão, apresentamos uma proposta de um modelo fisiopatológico para explicar o comportamento apático na doença de Alzheimer, combinando dados de neuropatologia, neuroimagem e experimentação animal sobre o papel do córtex órbito-frontal, cíngulo anterior, núcleos da base e dopamina na neurobiologia da tomada de decisão.

PALAVRAS-CHAVE: apatia, doença de Alzheimer, tomada de decisão, córtex órbito-frontal, córtex cingulado anterior, núcleos da base, dopamina.

Alzheimer's disease (AD) is the most frequent cause of dementia, ${ }^{1,2}$. The cognitive and functional decline characteristics of the disease are accompanied by behavioral disturbances in almost $90 \%$ of patients ${ }^{3}$. Behavioral and psychological symptoms of dementia (BPSD) represent significant clinical problems, resulting in accelerated functional decline $^{4}$, caregiver distress ${ }^{5}$, aggression towards patient ${ }^{6}$, institutionalization ${ }^{7,8}$ and possibly increased mortality ${ }^{9}$.

The most common BPSD, particularly in AD, is apathy ${ }^{10-12}$. In this article, we present a review on the neurobiological aspects of the apathetic syndrome in $A D$, gathering information from experimental and clinical/neuroimaging studies. Our goal is to provide an anatomo-functional model of apathy in the disease and to discuss some of its therapeutic implications. In this review, we will discuss apathetic behavior as a disorder of reward-related decision-making. Also, neuroimaging and pathological data from $A D$ apathetic patients will be reviewed, reconciling the implicated structures with experimental research and functional neuroimaging data from decision-making models. Finally, we have proposed a new framework to understand apathy in AD, and perhaps in other conditions, while discussing possible therapeutic alternatives.

\section{Apathy definition, epidemiology,}

diagnosis and clinical implications

Marin defined apathy as "a lack of motivation not attributable to diminished level of conscience, cognitive impairment or emotional distress"'13. Recently, Levy and Du-

\footnotetext{
'Grupo de Pesquisa em Neurologia Cognitiva e do Comportamento, Departamento de Clínica Médica da Faculdade de Medicina da Universidade Federal de Minas Gerais (UFMG), Belo Horizonte, Brasil; ${ }^{2}$ INSERM U610, F-75013, UPMC Univ Paris 06, F-75005, AP-HP, Hôpital Saint-Antoine, Service de Neurologie, F-75012, Paris, France.
} 
bois ${ }^{14}$ proposed a phenomenological approach to define apathy, considering it as a "quantitative reduction of selfgenerated voluntary and purposeful behaviors". According to this contemporary view, apathy may be caused by dysfunction of any steps necessary to achieve goal-directed behavior as follows: internal and external determinants that motivate behavior, selection of goals, elaboration of a plan of action, initiation, execution, evaluation of goals achieved and feedback control of the behavior response. Hence, it is hardly surprising that this complex set of processes may be compromised in demented patients, especially in advanced stages of disease ${ }^{10}$.

Apathy has been shown to be the most common behavioral change in $A D^{10-12}$. Its prevalence depends on the type of population studied, the diagnostic criteria and the type or severity of dementia. When diagnosed with the Neuropsychiatric Inventory (NPI) $)^{15}$ in outpatient settings, apathy prevalence ranged from $55 \%{ }^{16}$ to $80 \%{ }^{17}$, and from $36 \%{ }^{12}$ to $53.3 \%{ }^{18}$ in community based samples of AD patients. van Reekum and coworkers' pooled analysis found a point prevalence of $60.3 \%$ in outpatients with $A D^{19}$.

Apathy is somewhat difficult to isolate from depression: apathy is often a symptom observed in depression. However, apathy can occur without depression in AD and when depression and apathy co-occur in AD patients, it has been shown that they are clinically and anatomically independent ${ }^{20-22}$. Indeed, in order to discriminate apathy from depression, several scales have been designed to quantify apathy, which wisely exclude symptoms such as sadness and negative thoughts, typically observed in depressive syndromes ${ }^{15,23-27}$.

There is now a large body of clinical evidence that apathy has construct validity with particular phenomenological, prognostic and therapeutic features ${ }^{28}$ :

1. The typical apathetic patient usually lacks the negative thoughts, sadness and somatic complaints frequently observed in mood disorders ${ }^{22}$. Furthermore, apathy has been associated with extrapyramidal signs ${ }^{29}$ and neuropsychological deficits which cannot be explained by depressive symptoms ${ }^{30,31}$.

2. Apathetic symptoms are predictors of worse clinical outcomes in prospective studies: $\mathrm{MCl}$ patients with high apathy scores have increased risk of dementia at follow-up ${ }^{32}$; apathetic AD patients have faster functional and cognitive decline ${ }^{33}$. Additionally, apathy seems to be more prevalent as dementia progresses ${ }^{10,34}$ and is also a relatively permanent behavior once following onset ${ }^{11}$, in contrast to depression whose prevalence appears to be reduced in advanced stages ${ }^{34-36}$. Furthermore, factor analysis of neuropsychiatric symptoms in dementia has repeatedly shown a division of depression and apathy into separate behavioral dimensions $s^{37,38}$.
3. Response to treatment is also different: anti-depressants, especially selective serotonin reuptake inhibitors (SSRI), seem to have no therapeutic benefit in apathetic patients or can even increase the severity of apathy ${ }^{39}$. Indeed, it has recently been shown that elderly depressed patients on SSRI had elevated apathy scores despite similar improvement in depressive symptoms when compared to the group treated with other anti-depressants ${ }^{40}$. Alternatively, Padala and coworkers documented a dissociation between apathetic symptom improvement and absence of global depression score change in a depressed patient treated with methylphenidate ${ }^{41}$.

\section{Prefrontal cortex-basal ganglia circuits and generation of voluntary actions}

The basal ganglia and their connections with prefrontal cortex (PFC) are essential to decision-making ${ }^{42,43}$. Hence, it is not surprising that fronto-striatal circuit dysfunction may be responsible for the emergence of apathetic behavior in a wide range of neurological disorders $^{13}$. According to Levy and Dubois, apathy must be understood as a heterogeneous disorder, resulting from at least three different phenomena related to distinct basal ganglia topography ${ }^{14}$. The first, ascribed to affective-emotional processing, involves the ventromedial PFC and its connection with the ventral striatum and amygdala. This circuit integrates the affective or emotional value of a given stimulus into the ongoing behavior. The second, ascribed to cognitive processing, involves the lateral PFC and the dorsal caudate nucleus. Essentially, this circuit is responsible for the executive elaboration of the plan of actions responsible for goal-directed behavior. The third, "auto-activation" processing, is observed in the most severe forms of apathy, characterized by difficulties in selfinitiating actions or thoughts, contrasting with relatively spared, externally driven response. This pattern, called the "auto-activation deficit" may be observed after bilateral lesions in the internal portions of the pallidum ${ }^{44,45}$, or after extensive damage to the medial wall of the $\mathrm{PFC}^{46}$. The latter topography of lesion, however, may not represent a good framework to understand apathy in as far as its great extension makes it difficult to draw specific functional conclusions.

The basal ganglia combine spatial segregation, because of its multiple parallel circuits connecting different PFC regions $^{47}$, and signal convergence ${ }^{48}$, displaying progressive concentration of fibers from cortex into the pallidum. This structural arrangement makes these structures a suitable place to extract a relevant signal from background noise arising from multiple input (parallel loops), and to amplify it throughout its final pathway. The resulting selection is 
then transferred back to the PFC, generating relevant neural signals in output targets such as cognitive and limbic territories, especially the medial PFC. Thus, the unequivocal importance of basal ganglia in the generation of behavior output should be taken in conjunction with clinical, pathological and neuroimaging findings from $A D$ patients in any attempt to understand apathy in this type of dementia.

Evidence from mild cognitive impairment $(\mathrm{MCl})$ patients and pre-dementia depressive syndromes point to the clinical relevance of apathetic behavior, even in early stages of cognitive decline ${ }^{49}$. The neuropsychological profile of apathetic patients with $\mathrm{MCl}$ who have converted to $A D$ gives interesting insight into the neuroanatomy of apathy. Robert and colleagues showed that an apathetic $\mathrm{MCl}$ group performed significantly worse in free recall memory tests, without concomitant deficits in other tests of executive functions ${ }^{31}$, in contrast with previous evidence from more advanced demented patients ${ }^{30}$. We believe that an executive default in activating strategies for retrieval from episodic memory might be a suitable explanation for these findings. Nevertheless, another possible interpretation is that apathy and free recall memory deficits are not related in terms of pathophysiology, but instead, their co-occurrence in $\mathrm{MCl}$ patients with higher conversion rates to dementia, might be an expression of additional $A D$ type pathology, extending from medial temporal lobe to basal forebrain involvement.

We propose that in early stages of $A D$, apathy may be the result of a dysfunction of affective-emotional processing, which takes place in ventromedial PFC, i.e. medial orbito-frontal cortex (OFC) and ventral medial PFC, and its connections with amygdala and nucleus accumbens, leading to impairment in striatum dopaminergic activation. In fact, it has previously been shown that neuropathological progression in AD, targets the ventromedial portions of frontal as early as temporal cortex, with the exception of entorhinal portions, and precedes parietal and lateral frontal cortex involvement ${ }^{50}$. Indeed, recent evidence with positron emission tomography using Abeta tracer [11(C)] "Pittsburg compound -B" (PIB) in mild and very mild $A D$ dementia disclosed early frontal pathology, especially in ventral portions ${ }^{51}$.

\section{Apathy, Alzheimer's disease and other cortical dementias: neuropathological and neuroimaging data}

Both pathological and functional imaging studies have implicated anterior cingulate cortex (ACC) and orbitofrontal cortex (OFC) in apathy associated with dementia, especially $A D$. Pathological data from $A D$ patients with severe dementia disclosed correlation between ACC pathol- ogy and apathy severity, according to NPI scores ${ }^{52}$. These findings were recently replicated in structural magnetic resonance imaging data ${ }^{53}$. Additionally, a series of studies with single photon emission tomography (SPECT) have shown resting hypometabolism in ACC from AD apathetic patients when compared to non-apathetic individual $s^{54-58}$. These findings are in agreement with experimental research ascribing a pivotal role to ACC in the human decision-making process ${ }^{59}$. Some of the same researchers also found hypometabolism in OFC regions, in addition to ACC dysfunction ${ }^{56,57}$. Lanctot and colleagues found similar results, showing decreased metabolism in left ACC and right OFC in AD apathetic patients scanned with SPECT ${ }^{60}$. More recently, Marshall and colleagues, employing PET in AD patients with mild to moderate dementia, showed that apathy was related to hypometabolism in ventromedial PFC, including the ventral $A C C$ and medial $\mathrm{OFC}^{61}$, as predicted and described below in our proposed account for neurobiology of apathy in AD. PET data from frontal variant of frontotemporal dementia (fvFTD) has also shown a significant relationship between apathy and OFC hypometabo$\operatorname{lism}^{62}$. It should be stressed that given decision-making is a dynamic process, resting PET or SPECT may lack the optimal spatio-temporal resolution to infer the underlying behavioral neurophysiology ${ }^{63}$, and may have higher sensitivity in more advanced stages of dementia. However, most of the functional neuroimaging data available so far display few conflicting issues and point to ventromedial PFC dysfunction as the background of apathetic behavior in cortical dementias. These data are in accordance with nonhuman primate and rodent research, and also fMRI in human studies, which strongly advocate the involvement of medial orbito-frontal regions and medial portions of PFC, especially ACC, in the human decision-making process ${ }^{64}$.

\section{Ventromedial prefrontal cortex and dopamine: decoding decision values and their translation into action}

There are several issues that must be considered when a subject engages in a decision-making process. $\mathrm{He} / \mathrm{she}$ should be capable of attributing value to potential outcomes; any desired goal must have a reasonable probability of achievement; Biologically relevant outcomes must be reasonably predictable; a plan of action must be selected in order to pursue reward or otherwise avoid punishment; the subject must discern not just the appropriate response but also the timing to execute it and the optimal response rate; and finally, demanding efforts and any delay to goal achievement must be factored in as action cost. Once this sophisticated processing concludes, top-down activation of behavioral output structures must 
take place. These statements are based on an economic point of view and provide a useful framework to understand animal decision-making ${ }^{65}$.

Data from non-primate research on decision-making suggests that OFC is critically involved in the prediction of reward outcomes, but not in the computation of outcome value ${ }^{66}$. Conversely, the medial PFC, especially rat pre-limbic and infra-limbic regions, has been associated with outcome value learning and encoding ${ }^{67}$, in addition to dorsomedial striatum ${ }^{68}$ and basolateral amygdala ${ }^{69}$. Nevertheless, primate single-unit neuron recordings $s^{70-72}$, and human functional neuroimaging studies ${ }^{73-75}$ have clearly shown that medial OFC is involved in outcome value encoding ${ }^{76}$, even when accounting for subjective preferences ${ }^{77}$. Furthermore, the pattern of connections between primate medial OFC resembles that of rat medial $\mathrm{PFC}^{78}$, suggesting that humans ventromedial PFC, including OFC, incorporated the outcome value processing ascribed to rat pre and infra-limbic medial frontal cortex ${ }^{79}$. Additional support for this claim comes from human studies showing that reward predictability activates more lateral portions of $\mathrm{OFC}^{80}$, a region connected to the medial OFC network, but which receives heavy inputs from different sensorial modalities, especially visual associative cortex ${ }^{81}$.

ACC has been repeatedly involved in primate decisionmaking tasks ${ }^{82}$. Its role has been ascribed to a wide range of activities: conflict monitoring, error monitoring and detection $^{83,84}$, response selection ${ }^{85}$, attention control ${ }^{86}$, pain affective processing ${ }^{87,88}$, social cognition ${ }^{89}$, reward probability processing ${ }^{90}$ and autonomic activation ${ }^{91}$. The reason for the high number of proposed functions remains poorly understood. However, a possible explanation derives from the acknowledgement that ACC is both structurally and functionally heterogeneous ${ }^{92}$, having a wide range of connections with other PFC regions, subcortical limbic, and motor output structures ${ }^{93}$. There seems to be a dorsal/ventral and a rostral/caudal specialization within the $\mathrm{ACC}^{94,95}$. Current understanding regarding $A C C$ in decision-making suggests that this region is critically involved in adaptative learning of decision values in a changing environment ${ }^{59}$. Kennerley and colleagues have shown that monkeys with ACC lesions fail to make the optimal decision choices based on previous gain and losses, when reward/action contingencies are manipulated ${ }^{96}$. Furthermore, Behrens and colleagues presented compelling evidence of ACC activation in tasks simulating naturalistic settings of "environmental volatility", whereby reward probabilities were dynamically manipulated ${ }^{90}$.

The optimal computation of decision values must take into account several reward features, such as magnitude, contextual valence, predictability and probabili- ty; and lastly, the costs necessary for goal achievement. Rat experimental research suggests a pivotal involvement of ACC in effort-related decision-making ${ }^{97}$. Indeed, Rudebeck and colleagues described this issue by showing a double dissociation between OFC and ACC, when processing delay and effort costs of actions. OFC lesioned rats displayed impulsive choices, being unable to wait for larger food reward; conversely, ACC lesioned animals had normal delayed responses but impaired effort-based decision-making, avoiding increased effort choices even though reward was four times higher ${ }^{98}$.

Hence what could produce the link between OFC and ACC processing of decision values and subsequent activation of motor output structures?

Dopamine plays a critical role in determining response rates in reward-related behavior and is essential to effortrelated decision-making ${ }^{99}$. Dopaminergic antagonist infusion either systemically ${ }^{100}$, or within the nucleus accumbens ${ }^{101}$ substantially reduces response vigor in food seeking behavior or, otherwise bias action selection away from effortful choices, even when reward offers are considered worthy. It is well known that patients under high dopamine receptor antagonism can display severe apathetic behavior ${ }^{102}$. Further support for this notion is found in non-primate research on drug seeking behavior reinstatement, which is a suitable model of drug addiction relapse after a period of abstinence ${ }^{103}$. When triggered by stress, drug cues or drug per se, reinstatement constitutes a highly motivated behavior ${ }^{104}$, and is virtually abolished by lesions in ventral tegmental area ${ }^{105}$ or dopamine antagonist infusion into dorsal striatum ${ }^{106}$. Additionally, human functional neuroimaging data suggest that the intense desire that motivates drug seeking depends on primary processing of drug-related cues in OFC ${ }^{107-109}$.

In a recent paper entitled "How the brain translates money into force", Pessiglione and colleagues submitted individuals to an incentive-force task, whereby images of three different amounts of monetary rewards could be earned by a strong hand-gripping response. They found that greater offers of money correlated with higher scores on grip force and skin conductance. These motivational measures were also strongly correlated with ventral striatum activation, where nucleus accumbens lies ${ }^{110}$. Using the same experimental paradigm, Schimdt and coworkers showed that patients with bilateral basal ganglia lesions, and Parkinson's disease patients on L-dopa deprivation, displayed impaired incentive motivation behavior, again implicating dopamine and striatum in translating value into action"1".

Indeed, there is a large body of functional neuroimaging data implicating ventral striatum in reward pro- 
cessing ${ }^{112}$. The accumbens role in incentive processing has been further clarified in another recent study. Cooper and Knutson, submitting humans to an incentive monetary task, have found accumbens activity corresponding both to valence, that is gain vs. loss trials; and salience, i.e. uncertain vs. certain outcomes ${ }^{113}$. A salient stimulus signals that a response will be necessary in the near future, that is, approaching an unexpected reward or running away from an environmental danger. This dual process account of accumbens function in incentive motivation behavior, suggests instead, that this structure may be a critical node in a circuitry, through which PFC processing of biologically significant stimuli, either valued or salient could trigger down-regulated structures in order to select the most appropriate response.

Belin and Everitt, using a behavior paradigm of drug seeking reinstatement in rodents, found evidence that could bridge the gap between value assessment in PFC and activation of output structures, such as fronto-striatal circuits. Their findings implicated ventral striatum as a critical node link to midbrain dopaminergic activation of dorsal striatum ${ }^{114}$. This study seems to give the first functional supporting evidence for Haber's proposed model of serial connectivity from ventral to dorsolateral striatum regions, through the midbrain dopamine system: the so-called striato-nigro-striatal spiraling connections ${ }^{115}$. According to this model, ventral tegmental area receives in- put from the accumbens and projects back both to ventral and central striatum, which in turn projects back to midbrain, into substantia nigra, where classical nigrostriatal afferents arise towards dorsal striatum.

\section{CONCLUSIONS}

Pooling functional neuroimaging evidence from ventromedial PFC hypometabolism displayed by apathetic AD patients together with experimental data implicating this region in decision-making, we propose a mechanism for reduced activation of goal-directed behaviors in these patients (Figure). Dysfunction of action/outcome evaluation, executed by OFC, ACC and basolateral amygdala interactions, compromise optimal computation of outcome value, probability and action-related costs. This deficit disrupts appropriate transmission of decision value signal into nucleus accumbens, determining no activation of the midbrain dopaminergic ascending pathways, which are necessary for the engagement of dorsal striatum. Deprived of appropriate dopamine signaling, the latter structure becomes deficient in extracting the most appropriate response to be executed from intersected fronto-striatal circuits,

Given PFC ventromedial areas are major targets of mesocorticolimbic dopamine projections ${ }^{116}$, and that there is experimental evidence of dopamine local modulation

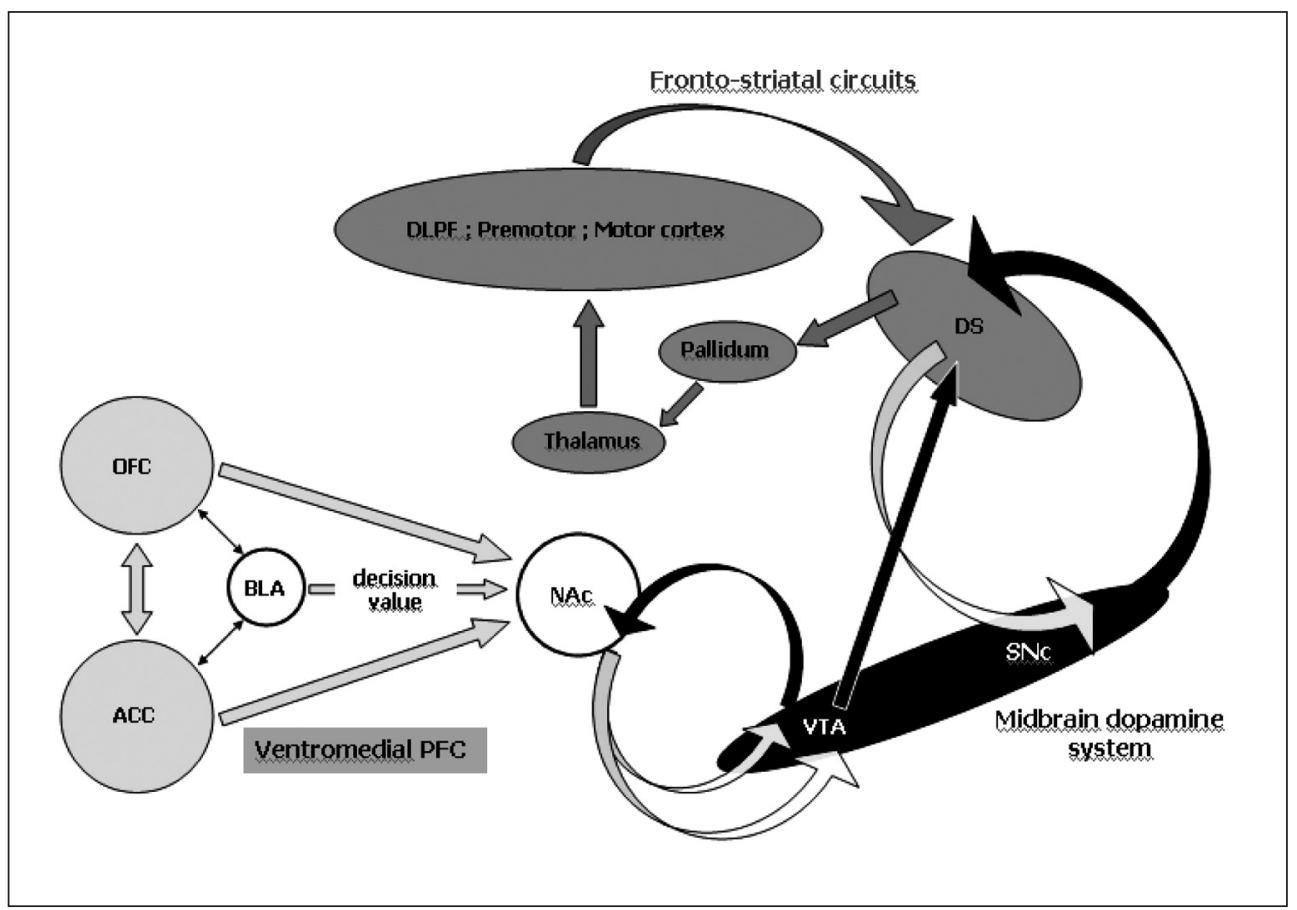

Figure. Proposed model of ventromedial PFC top-down influence on behavior generation. OFC, orbito-frontal cortex; ACC, anterior cingulate cortex; BLA, basolateral amygdala; NAc, nucleus accumbens core; VTA, ventral tegmental area; SNc, substantia nigra pars compacta; DS, dorsal striatum; DLPF, dorsolateral prefrontal. 
of goal-directed behavior ${ }^{117}$, it is reasonable to hypothesize that enhancement of dopaminergic neurotransmission might improve apathetic symptoms. Indeed, there are anecdotal successful reports using this pharmacological strategy ${ }^{118-121}$. Accordingly, Czernecki and coworkers showed in a recent open label trial that Parkinson's disease patients, submitted to subthalamic nucleus stimulation, had unequivocal improvement in apathetic behavior measures after treatment with dopaminergic agonist ${ }^{122}$. Nevertheless, there is a need to test this hypothesis using a clinical trial design, and recruiting a reasonable number of subjects with clinically meaningful apathy. It is worth noting that this approach might not be successful if cognitive impairment is severe enough to compromise the executive elaboration of a goal-directed plan, as should be observed in more advanced demented subjects. It is also possible that cognitive improvement might explain the positive effects of cholinergic therapy on apathy measures of $A D$ patients ${ }^{123,124}$.

This model also predicts that apathetic behavior should be related to cognitive abilities attributed to OFC, such as reversal learning, and that sympathetic arousal should also be disrupted, which could easily be tested in future research.

Obviously, this hypothetic model of ventromedial PFC dysfunction in $A D$ apathy remains speculative and requires experimental confirmation, preferentially with functional neuroimaging techniques, employing reward related behavioral tasks, as has recently been studied in mania ${ }^{125}$, psychosis $^{126}$, obsessive compulsive disorder ${ }^{127}$, and pathological gambling ${ }^{128}$. Employing new research methodology, it would be no surprise to find distinct subtypes of apathetic patients, as has been previously suggested ${ }^{14}$. Undoubtedly, this effort could provide great insight into apathy neurobiology, aiding the development of new therapeutic strategies for this disturbing behavior in a wide range of neuropsychiatric disorders.

\section{REFERENCES}

1. Herrera E Jr, Caramelli P, Silveira AS, Nitrini R. Epidemiologic survey of dementia in a community-dwelling Brazilian population. Alzheimer Dis Assoc Disord 2002;16:103-108.

2. Hirtz D, Thurman DJ, Gwinn-Hardy K, Mohamed M, Chaudhuri AR, Zalutsky R. How common are the "common" neurologic disorders? Neurology 2007;68:326-337.

3. Bozzola FG, Gorelick FB, Freels S. Personality changes in Alzheimer's disease. Arch Neurology 1992;49:297-300.

4. Harwood DG, Barker WW, Ownby RL, Duara R. Relationship of behavioral and psychological symptoms to cognitive impairment and functional status in Alzheimer's disease. Int J Geriatr Psychiatry 2000;15:393-400

5. Tan LL, Wong HB, Allen H. The impact of neuropsychiatric symptoms of dementia on distress in family and professional caregivers in Singapore. Int Psychogeriatr 2005;17:253-263.

6. Sasaki M, Arai Y, Kumamoto K, Abe K, Arai A, Mizuno Y. Factors related to potentially harmful behaviors towards disabled older people by family caregivers in Japan. Int J Geriatr Psychiatry 2007;22:250-257.

7. Magni E, Binetti G, Bianchetti A, Trabucchi M. Risk of mortality and in- stitutionalization in demented patients with delusions. J Geriatr Psychiatry Neurol 1996;9:123-126.

8. Scarmeas N, Brandt J, Albert M, Hadjigeorgiou G, Papadimitriou A Dubois B, et al. Delusions and hallucinations are associated with worse outcome in Alzheimer disease. Arch Neurol 2005;62: 1601-1608.

9. Tun SM, Murman DL, Long HL, Colenda CC, von Eye A. Predictive validity of neuropsychiatric subgroups on nursing home placement and survival in patients with Alzheimer disease. Am J Geriatr Psychiatry 2007;15:314-332.

10. Onyike CU, Sheppard JM, Tschanz JT, Norton MC, Green RC, Steinberg $\mathrm{M}$, et al. Epidemiology of apathy in older adults: The Cache County study. Am J Geriatr Psychiatry 2007;15:365-375.

11. Craig D, Mirakhur A, Hart DJ, McIlroy SP, Passmore AP. A cross-sectional study of neuropsychiatric symptoms in 435 patients with Alzheimer's disease. Am J Geriatr Psychiatry 2005; 13:460-468.

12. Lyketsos CG, Lopez O, Jones B, Fitzpatrick AL, Breitner J, DeKosky S. Prevalence of neuropsychiatric symptoms in dementia and mild cognitive impairment: results from the cardiovascular health study. JAMA 2002;288:1475-1483.

13. Marin RS. Apathy: a neuropsychiatric syndrome. J Neuropsychiatry Clin Neurosci 1991; 3:243-254.

14. Levy R, Dubois B. Apahy and functional anatomy of the prefrontal cortex-basal ganglia circuits. Cereb Cortex 2006;16:916-928

15. Cummings JL, Mega M, Gray K, Rosemberg-Thompson S, Carusi DA, Gornbein J. The Neuropsychiatric Inventory: comprehensive assessments of psychopathology in dementia. Neurology 1994;44:2308-2313.

16. Aharon-Peretz J, Kliot D, Tomer R. Behavioral differences between white matter lacunar dementia and Alzheimer's disease: a comparison on the neuropsychiatric inventory. Dement Geriatr Cogn Disord 2000;11:294-298.

17. Craig AH, Cummings JL, Fairbanks L, Itti L, Miller BL, Li J, et al. Cerebral blood flow correlates of apathy in Alzheimer disease. Arch Neurol 1996;53:1116-1120.

18. Tatsch MF, Bottino CM, Azevedo D, et al. Neuropsychiatric symptoms in Alzheimer disease and cognitively impaired, nondemented elderly from a community-based sample in Brazil: prevalence and relationship with dementia severity. Am J Geriatr Psychiatry 2006;14:438-445.

19. van Reekum R, Stuss DT, Ostrander L. Apathy: why care? J Neuropsychiatry Clin Neurosci 2005;17:7-19.

20. Andersson S, Krogstad JM, Finset A. Apathy and depressed mood in acquired brain damage: relationship to lesion localization and psychophysiological reactivity. Psychol Med 1999;29:447-456.

21. Kuzis G, Sabe L, Tiberti C, Merello M, Leiguarda R, Starktein SE. Explicit and implicit learning in patients with Alzheimer disease and Parkinson disease with dementia. Neuropsychiatry Neuropsychol Behav Neurol 1999;12:265-269.

22. Levy ML, Cummings JL, Fairbanks LA, et al. Apathy is not depression. J Neuropsychiatry Clin Neurosci 1998;10:314-319.

23. Marin RS, Biedrzycki RC, Firinciogullari S. Reliability and validity of the apathy evaluation scale. Psychiatry Research 1991;38:143-162.

24. Starkstein SE, Mayberg HS, Preziosi TJ, Andrezejewski P, Leiguarda R, Robinson RG. Reliability, validity and clinical correlate of apathy in Parkinsons's disease. J Neuropsychiatry Cli Neurosci 1992;4;134-139.

25. Robert PH, Clairet S, Benoit M, et al. The Apathy Inventory: assessment of apathy and awareness in Alzheimer'disease, Parkinson's disease and mild cognitive impairment. Int j Geriatr Psychiatry 2002;17:1099-1105.

26. Sockeel P, Dujardin P, Devos D, Denève C, Destée A, Defebvre L.The Lille apathy rating scale (LARS), a new instrument for detecting and quantifying apathy: validation in Parkinson's disease. J Neurol Neurosurg Psychiatry 2006;77:579-584.

27. Lueken U, Seidl U, Völker L, Schweiger E, Kruse A, Schröder J. Development of a short version of the Apathy Evaluation Scale specifically adapted for demented nursing home residents. Am J Geriatr Psychiatry 2007;15:376-385.

28. Teixeira, AL Jr, Caramelli, P. Apathy in Alzheimer's disease. Rev Bras Psiquiatr 2006;28:238-241.

29. Starkstein SE, Sabe L, Vázquez S, et al. Neuropsychological, psychiatry, and cerebral perfusion correlates of leukoaraiosis in Alzheimer's disease. J Neurol Neurosurg Psychiatry 1997;63:66-73.

30. McPherson S, Fairbanks L, Tekin S, Cummings JL, Back-Madruga C. Apathy and executive function in Alzheimer's disease. J Int Neuropsychol Soc 2002;8:373-381.

31. Robert PH, Berr C, Volteau M, et al. Neuropsychological performance in mild cognitive impairment with and without apathy. Dement Geriatr Cogn Disord 2006;21:192-197.

32. Robert PH, Berr C, Volteau M, et al. Apathy in patients with mild cognitive impairment and the risk of developing dementia of Alzheimer's 
disease: a one-year follow-up study. Clin Neurol Neurosurg 2006;108: 733-736.

33. Starkstein SE, Jorge R, Mizrahi R, Robinson RG. A prospective longitudinal study of apathy in Alzheimer's disease. J Neurol Neurosurg Psychiatry 2006;77:8-11.

34. Aalten P, De Vugt ME, Jaspers N, Jolles J, Verhey FR. The course of neuropsychiatric symptoms in dementia. Part I: findings from the two-year longitudinal Maasbed study. Int J Geriatr Psychiatry 2005;20:523-530.

35. Lopez OL, Becker JT, Sweet RA, et al. Psychiatric symptoms vary with the severity of dementia in probable Alzheimer's disease. J Neuropsychiatry Clin Neurosci 2003;15:346-353.

36. Zuidema SU, Derksen E, Verhey FR, Koopmans RT. Prevalence of neuropsychiatric symptoms in a large sample of Dutch nursing home patients with dementia. Int J Geriat Psychiatry 2007;22: 632-638.

37. Zuidema SU, de Jonghe JF, Verhey FR, Koopmans RT. Neuropsychiatric symptoms in nursing home patients: factor structure invariance of the Dutch nursing home version of the neuropsychiatric inventory in different stages of dementia. Dement Geriatr Cogn Disord 2007;24:169-176.

38. Aalten P, Verhey FR, Boziki M, et al. Neuropsychiatric Syndromes in Dementia. Results from the European Alzheimer Disease Consortium: Part I. Dement Geriatr Cogn Disord 2007;24:457-463.

39. Barnhart WJ, Makela EH, Latocha MJ. SSRI-induced apathy syndrome: a clinical review. J Psychiatry Pract 2004;10:196-199.

40. Wongpakaran N, van Reekum R, Wongpakaran T, Clarke D. Selective serotonin reuptake inhibitors associates with apathy among depressed elderly: a case-control study. Ann Gen Psychiatry 2007;6:7.

41. Padala PR, Petty F, Bhatia SC. Methylphenidate may treat apathy independent of depression. Ann Pharmacother 2005;39:1947-1949.

42. Delgado MR. Reward-related responses in the human striatum. Ann N Y Acad Sci 2007;1104:70-88.

43. Balleine BW, Delgado MR, Hikosaka O. The role of the dorsal striatum in reward and decision-making. J Neurosci 2007;27:8161-8165.

44. Starkstein SE, Berthier ML, Leiguarda R. Psychic akinesia following bilateral pallidal lesions. Int J Psychiatry Med 1989;19:155-164.

45. Lugaresi A, Montagna P, Morreale A, Gallassi R. 'Psychic akinesia' following carbon monoxide poisoning. Eur Neurol 1990;30:167-169.

46. Kumral E, Bayulkem G, Evyapan D, Yunten N. Spectrum of anterior cerebral artery territory infarction: clinical and MRI findings. Eur J Neurol 2002;9:615-624.

47. Alexander GE, DeLong MR, Strick PL. Parallel organization of functionally segregated circuits linking basal ganglia and cortex. Annu Rev Neurosci 1986;9:357-381.

48. Haber SN, Kim KS, Mailly P, Calzavara R. Reward-related cortical inputs define a large striatal region in primates that interface with associative cortical connections, providing a substrate for incentive-based learning. J Neurosci 2006;26:8368-8376.

49. Bartolini M, Coccia M, Luzzi S, Provinciali L, Ceravolo MG. Motivational symptoms of depression mask preclinical Alzheimer's disease in elderly subjects. Dement Geriatr Cogn Disord 2005;19:31-36.

50. Chu CC, Tranel D, Damasio AR, Van Hoesen GW. The autonomic-related cortex: pathology in Alzheimer's disease. Cereb Cortex 1997;7:86-95.

51. Mintun MA, Larossa GN, Sheline YI, et al. [11C]PIB in a nondemented population: potential antecedent marker of Alzheimer disease. Neurology 2006;67:446-52.

52. Marshall GA, Fairbanks LA, Tekin S, Vinters HV, Cummings JL. Neuropathological correlates of apathy in Alzheimer's disease. Dement Geriatr Cogn Disord 2006;21:144-147.

53. Apostolova LG, Akopyan GG, Partiali N, et al. Structural correlates of apathy in Alzheimer's disease. Dement Geriatr Cogn Disord 2007;27:91-97.

54. Migneco O, Benoit M, Koulibaly PM, et al. Perfusion brain SPECT and statistical parametric mapping analysis indicate that apathy is a cingulate syndrome: a study in Alzheimer's disease and nondemented patients. Neuroimage 2001;13:896-902.

55. Benoit M, Dygai I, Migneco O, et al. Behavioral and psychological symptoms in Alzheimer's disease. Relation between apathy and regional cerebral perfusion. Dement Geriat Cogn Disord 1999;10:511-517.

56. Benoit M, Kounibaly PM, Migneco O, Darcourt J, Pringuey DJ, Robert $\mathrm{PH}$. Brain perfusion in Alzheimer's disease with and without apathy: a SPECT study with statistical parametric mapping analysis. Psychiatry Res 2002;114:103-111

57. Benoit M, Clairet S, Koulibaly PA, Darcourt J, Robert PH. Brain perfusion correlates of the apathy inventory dimensions of Alzheimer's disease. Int J Geriatr Psychiatry 2004;19:864-869.

58. Robert PH, Darcourt G, Koulibaly MP, et al. Lack of initiative and interest in Alzheimer's disease: a single photon emission computed tomography study. Eur J Neurol 2006;13:729-735.
59. Rushworth MF, Behrens TE. Choice, uncertainty and value in prefrontal and cingulate cortex. Nat Neurosci 2008;11:389-397.

60. Lanctôt KL, Moosa S, Hermann N, et al. A SPECT study of apathy in Alzheimer's disease. Dement Geriatr Cogn Disord 2007;24:65-72.

61. Marshall GA, Montserratt L, Harwood D, Mandelkern M, Cummings JL, Sultzer DL. Positron emission tomography metabolic correlates of apathy in Alzheimer's disease. Arch Neurol 2007;64:1015-1020.

62. Peters F, Perani D, Herholz K, et al. Orbitofrontal dysfunction related to both apathy and desinhibition in frontotemporal dementia. Dement Geriatr Cogn Disord. 2006;21:373-379.

63. Knutson B, Cooper JC. Functional magnetic resonance imaging of reward prediction. Curr Opin Neurol 2005;18:411-417.

64. Rushworth MF, Behrens TE, Rudebeck PH, Walton ME. Contrasting holes for cingulate and orbitofrontal cortex in decisions and social behavior. Trends Cogn Sci 2007;11:168-176.

65. Platt ML, Huettel SA. Risky business: the neuroeconomics of decision making under uncertainty. Nat Neurosci 2008;11:398-403.

66. Ostlund SB, Balleine BW. The contribution of orbitfrontal cortex to action selection. Ann N Y Acad Sci 2007;1121:174-192.

67. Balleine BW, Dickson Q. The role of incentive learning in instrumental outcome revaluation by sensory-specific satiety. Anim Learn Behav 1998;26:46-59.

68. Yin HH, Ostlund SB, Knowlton BJ, Balleine BW. The role of the dorsomedial striatum in instrumental conditioning. Eur J Neurosci 2005;22:513-523.

69. Balleine BW, Killcross AS, Dickinson A. The effect of lesions of the basolateral amygdala on instrumental conditioning. J Neurosci 2003;23:666-675.

70. Rolls ET, Baylis LL. Gustatory, olfactory, and visual convergence within the primate orbitofrontal cortex. J Neurosci 1994;14:5437-5452.

71. Critchley HD, Rolls ET. Hunger and satiety modify the responses of olfactory and visual neurons in the primate orbitofrontal cortex. J Neurophysiol 1996;75:1673-1686.

72. Rolls ET, Critchley HD, Browning AS, Hernadi I, Lenard L. Responses to the sensory properties of fat of neurons in the primate orbitofrontal cortex. J Neurosci 1999;19:1532-1540.

73. Anderson AK, Christoff K, Stappen I, et al. Dissociated neural representations of intensity and valence in human olfaction. Nat Neurosci 2003;6:196-202

74. Small DM, Gregory MD, Mak YE, Gitelman D, Mesulam MM, Parrish T. Dissociation of neural representation of intensity and affective valuation in human gustation. Neuron 2003;39:701-711.

75. O’Doherty J, Winston J, Critchley H, Perrett D, Burt DM, Dolan RJ. Beauty in a smile: the role of medial orbitofrontal cortex in facial attractiveness. Neuropsychologia 2003;41:147-155.

76. O'Doherty J. Lights, Camembert, Action! The role of human orbitofrontal cortex in encoding stimuli, rewards and choices. Ann N Y Acad Sci 2007;1121:254-272.

77. Padoa-Schioppa C, Assad JA. The representation of economic value in the orbitofrontal cortex is invariant for changes of menu. Nat Neurosci 2008;11:95-102

78. Price JL. Definition of the orbital cortex in relation to specific connections with limbic and visceral structures and other cortical regions. Ann N Y Acad Sci 2007;1121:1154-1171.

79. Killcross S, Coutureau E. Coordination of actions and habits in the medial prefrontal cortex of rats. Cereb Cortex 2003;13:400-408.

80. O'Doherty JP, Deichmann R, Critchley HD, Dolan RJ. Neuron responses during anticipation of a primary taste reward. Neuron 2002;33:815-826.

81. Öngür D, Price JL. The organization of networks within the orbital and medial prefrontal cortex of rats, monkeys and humans. Cereb Cortex 2000;10:206-219.

82. Walton ME, Croxson PL, Behrens TE, Kennerley SW, Ruschworth MF. Adaptative decision making and value in the anterior cingulate cortex. Neuroimage 2007;36(Suppl 2):S142-S154.

83. Carter CS, Braver TS, Barch DM, Botvinick M, Noll D, Cohen JD. Anterior cingulate cortex, error detection, and the online monitoring of performance. Science 1998; 280:747-749.

84. Pochon JB, Riis J, Snafey AG, Nystron LE, CohenJD. Functional imaging of decision conflict. J Neurosci 2008;28:3468-3473.

85. Isomura $Y$, Ito $Y$, Akazawa T, Nambu A, Takada M. Neural coding for "attention for action" and "response selection" in primate anterior cingulate cortex. J Neurosci 2003;8002-8012.

86. Crottaz-Herbette S, Menon V. Where and when the anterior cingulate cortex modulates attentional response: combined fMRI and ERP evidence. J Cogn Neurosci 2006;18:766-780.

87. Johansen JP, Fields HL, Manning BH. The affective component of pain in rodents: direct evidence for a contribution of the anterior cingulate cortex. Proc Natl Acad Sci U S A 2001; 98:8077-8082. 
88. Wager TD, Scott DJ, Zubieta JK. Placebo effects on human mu-opioid activity during pain. Proc Natl Acad Sci U S A 2007;104:11056-11061.

89. Rudebeck PH, Buckley MJ, Walton ME, Rushworth MF. A role for the macaque anterior cingulate gyrus in social valuation. Science 2006; 313:1310-1312.

90. Behrens TE, Woolrich MW, Walton ME, Rushworth MF. Learning the value of information in an uncertain world. Nat Neurosci 2007;10:1214-1221.

91. Critchley HD, Mathias CJ, Josephs O, et al. Human cingulate cortex and autonomic control: converging neuroimaging and clinical evidence. Brain 2003;126:2139-2152.

92. Paus T. Primate anterior cingulate cortex: where motor control, drive and cognition interface. Nat Rev Neurosci 2001;2:417-424.

93. Nachev P. Cognition and medial frontal cortex in health and disease. Curr Opin Neurol 2006;19:586-592.

94. Margulies DF, Kelly AM, Uddin LQ, Biswal BB, Castellanos FX, Milham MP. Mapping the functional connectivity of anterior cingulate cortex. Neuroimage 2007;37:579-588.

95. Somervile LH. Heatherton TF, Kelley WM. Anterior cingulate cortex responds differentially to expectancy violation and social rejection. Nat Neurosci 2006;9:1007-1008.

96. Kennerley SW, Walton ME, Behrens TE, Buckley MJ, Rushworth MF. Optimal decision making and the anterior cingulate cortex. Nat Neurosci 2006;9: 940-947.

97. Walton ME, Bannerman DM, Alterescu K, Rushworth MF. Functional especialization within medial frontal cortex of the anterior cingulate for evaluating effort-related decisions. J Neurosci 2003;23:6475-6479.

98. Rudebeck PH, Walton ME, Smyth AN, Bannerman DM, Rushworth MF. Separate neural pathways process different decision costs. Nat Neurosci 2006;9:1161-1168

99. Salamone JD, Correa M, Farrar A, Mingote SM. Effort-related functions of nucleus accumbens dopamine and associated fore-brain circuits. Psychopharmacology 2007;191:461-482.

100. Cousins MS, Wei W, Slamanone JD. Pharmacological characterization of performance on a concurrent lever pressing / feeding choice procedure: effects of dopamine antagonist, cholinomimetic, sedative and stimulant drugs. Psychopharmacology 1994;116:529-537.

101. Nowend KL, Arizzi M, Carlson BB, Salamone JD. D1 or D2 antagonism in nucleus accumbens core and dorsomedial shell suppresses lever pressing for food but leads to compensatory increases in chow consumption. Pharmacol Biochem Behav 2001;69:373-382.

102. Artaloytia JF, Arango C, Lahti A, et al. Negative signs and symptoms secondary to antipsychotics: a double-blind, single dose of placebo, haloperidol, and risperidone in healthy volunteers. Am J Psychiatry 2006;163:488-493.

103. Shaham Y, Shalev U, Lu L, De Wit H, Stewart J. The reinstatement model of drug relapse: history, methodology and major findings. Psychopharmacology 2003;168:3-20.

104. Kalivas PW, McFarland K. Brain circuitry and the reinstatement of cocaine- seeking behavior. Psychopharmacology 2003;168:44-56.

105. Kalivas PW, Volkow ND. The neural basis of addiction: a pathology of motivation and choice. Am J Psychiatry 2005;162:1403-1413.

106. Vanderschuren LJ, Everitt BJ. Behavioral and neural mechanisms of compulsive drug seeking. Eur J Pharmacol 2005;526:77-88.

107. Volkow ND, Wang GJ, Ma Y, et al. Activation of orbital and medial prefrontal cortex by methylphenidate in cocaine-addicted subjects but not in controls: relevance to addiction. J Neurosci 2005;25:3932-3939.

108. Volkow ND, Wang GJ, Telang F, et al. Profound decreases in dopamine release in striatum in detoxified alcoholics: possible orbitofrontal involvement. J Neurosci 2007;27:12700-12706.
109. Volkow ND, Wang GJ, Telang F, et al. Dopamine increases in striatum does not elicit craving in cocaine abusers unless they are coupled with cocaine cues. Neuroimage 2008;39:1266-73.

110. Pessiglione M, Schmidt L, Draganski B, et al. How the brain translates money into force: a neuroimaging study of subliminal motivation. Science 2007;316:904-906.

111. Schmidt L, d'Arc F, Galanaud D, et al. Braking the bridge between money and force: dysfunction of incentive motivation following basal ganglia damage. Brain 2008. [Epub ahead of print]

112. Knutson B, Taylor J, Kaufman M, Peterson R, Glover G. Distributed neural representation of expected value. J Neurosci 2005;25: 4806-4012.

113. Cooper JC, Knutson B. Valence and salience contributes to nucleus accumbens activation. Neuroimage 2008;39:538-547.

114. Belin D, Everitt BJ. Cocaine seeking habits depend upon dopamine-dependent serial connectivity linking the ventral with the dorsal striatum. Neuron 2008;57:432-441.

115. Haber SN, Fudge JL, McFarland NR. Striatonigrostriatal pathways in primates form an ascending spiral from the shell to the dorsolateral striatum. J Neurosci 2000;20:2369-2382.

116. Willians SM, Goldman-Rakic PS. Widespread origin of the primate mesofrontal dopamine system. Cereb Cortex 1998;8:321-345.

117. Hitchcott PK, Quinn JJ, Taylor Jr. Bidirectional modulation of goaldirected actions by prefrontal cortical dopamine. Cereb Cortex 2007; 17:2820-2827.

118. Marin RS, Fogel BS, Hawkins J, Duffy J, Krupp B. Apathy: a treatable syndrome. J Neuropsychiatry Clin Neurosci 1995;7:23-30.

119. Galynker I, Ieronimo C, Miner C, Rosenblum J, Vilkas N, Rosenthal R. Methylphenidate treatment of negative symptoms in patients with dementia. J Neuropsychiatry Clin Neurosci 1997;9:231-239.

120. Padala PR, Burke WJ, Bhatia SC, Petty F. Treatment of apathy with methylphenidate. J Neuropsychiatry Clin Neurosci 2007;19:81-83.

121. Watanabe MD, Martin EM, DeLeon OA, Gaviria M, Pavel DJ, Trepashko DW. Successful methylphenidate treatment of apathy following subcortical infarcts. J Neuropsychiatry Clin Neurosci 1995;7:502-504.

122. Czernecki V, Schüpbach M, Yaici S, Levy R, Dubois B, Agid Y. Ropinirole improves apathy in patients with Parkinson disease and subthalamic nucleus stimulation. Mov Disord 2008 [Epub ahead of print]

123. Tanaka M, Namiki C, Thuy DH, et al. Prediction of psychiatry response to donepezil in patients with mild to moderate Alzheimer's disease. J Neurol Sci 2004; 225:135-141.

124. Cummings JL, Koumaras B, Chen M, Mirski D; Rivastigmine Nursing Home Study Team. Effects of rivastigmine treatment on the neuropsychiatric and behavioral disturbances of nursing home residents with moderate to severe probable Alzheimer's disease: a 26-week, multicenter, open-label study. Am J Geriatr Pharmacother 2005;3:137-148.

125. Abler B, Greenhouse I, Ongur D, Walter H, Heckers S. Abnormal reward system activation in mania. Neuropsychopharamcology 2007 [Epub ahead of print]

126. Murray GK, Corlett PR, Clark L, et al. Substantia nigra/ventral tegmental reward prediction error disruption in psychosis. Mol Psychiatry 2008;13:267-276.

127. Remijnse PL, Nielen MM, van Balkom AJ, et al. Reduced orbito-frontal striatal activity on a reversal learning task in obsessive compulsive disorder. Arch Gen Psychiatry 2006;63:1225-1236.

128. Reuter J, Raedler T, Rose M, Hand I, Gläscher J, Büchel C. Pathological gambling is linked to reduced activation of the mesolimbic reward system. Nat Neurosci 2005;8:147-148. 